\title{
On the Language Ability Building of Outbound Tour Leader
}

\author{
Jue Wang ${ }^{1, a}$, Chunxiang Luo ${ }^{2, b}$ \\ ${ }^{1}$ Tourism Department, Hainan TV\& Radio University, Haikou 570208, China; \\ ${ }^{2}$ Tourism Department, Hainan College of Economics and Business, Haikou 571127, China. \\ a826794242@qq.com, b754838397@qq.com
}

\begin{abstract}
The outbound tour leader plays a key role in helping tourists communicate abroad. The language ability of the tour leader consists of general language ability and communication language ability. The paper proposes some suggestions of building outbound tour leader's language ability, such as strengthening language application ability, enhancing the intercultural sensitivity, intensifying intercultural communication competence and enhancing the service ability, etc. to improve their language ability.
\end{abstract}

Keywords: outbound tour leader; general language ability; communication language ability; suggestions.

\section{Introduction}

The outbound tour leader has played a key role in helping tourist communicate in foreign countries. Therefore the leader's language ability becomes an important bridge in cultural communication and foreign communication. Their language ability consists of general language ability and communication language ability.

\section{Composition of Outbound Tour Leader's Language Ability}

\subsection{Composition of Outbound Tour Leader's General Language Ability}

Wei Hui, Deputy Director of the Language Application Institute in Ministry of Education, argues in 2015 that better interpersonal communicate results from language communication ability. Moreover, general language ability means the capability of communication, including native language (dialect) expression ability, general-purpose language application ability and foreign language ability. Undoubtedly, the general language ability of outbound tour leaders also includes the above three categories.

\subsubsection{Native language (Dialect) Expression Ability}

Zhang Haizhong and Yongzhi in 2010 believe that dialect and fellow-townsman identity are the main research content of regional psychology. In the category of regional psychology, the dialect is the core to studying the regional culture and regional psychological differences especially the regional culture psychological problems. With deep emotion, 'accent' is a sign of belonging. In a foreign land, when tourists hear the familiar accent, they will produce 'fellow-townsman identity' effect in regional psychology and consider themselves to be the members of fellow-townsman, which will reduce the psychological differences to some extent, ease the psychological pressure, reduce psychological conflicts and increase the cultural identity of intercultural communication. Outbound tour leaders in a foreign country should show the charm of the dialect, build their own language skills and establish authority in interpersonal communication.

\subsubsection{General-purpose Language Application Ability}

Chinses tourists in the same tour group are not necessarily coming from the same region of China. When they come to the foreign countries, they speak native language (Mandarin, the general-purpose language in China) which can ease the pressure of communication. The outbound tour leader should have a good command of general-purpose language (Mandarin) application ability. General-purpose language application ability can be divided into the beginner, intermediate and advanced level, depending on the level of tour leader's Mandarin application and bilingual verbal fluency, etc. They 
also should pay attention to the cooperative principle, etiquette rule of communication and the degree of correctness, standardization and appropriateness of general-purpose language application, and so on.

\subsubsection{Interpretation and Translation Ability}

Ding Chuang in 2008 argued that interpretation and translation are taking the symbols of language as medium and a complex thinking activity of information transfer between different cultures. Language and culture influence each other. As a medium of communication, translation is not only a kind of language communication, but also cross cultural communication. The leader should have the ability to translate foreign language, covering the ability of listening, speaking, reading and writing. It also requires outbound tour leaders to understand Chinese and foreign country's culture and thus their knowledge should cover all aspects of life, including tourism industry, culture, values, business, entertainment, health / medicine, law and transportation, etc.

\subsection{Composition of Outbound Tour Leader's Communication Language Ability}

Besides the basic language ability, the outbound tour leaders should also have following six language skills and good communication abilities.

\subsubsection{Shoulder the Responsibility}

Besides the foreign language skills, the leaders should have good service awareness and a sense of responsibility and use it in communication. When the tourists made mistakes or did wrong things, the tour leaders may blame it on themselves rather than on the tourists and take the initiative to assume responsibility. For example, an outbound tour leader once told us his experience: when going through customs, an old couple was discovered a package of food in their belongings obtained from the previous plane by the customs officers and would be fined, but they strongly disagreed. As a result, the atmosphere was tense. The leader explained and apologized to the customs officers that he did not tell the tourists about the relative rules clearly in advance and thus led to the mistakes, so he should be responsible for it. Finally, through effective mediation, the old couple was understood by the customs officer and wasn't be fined.

Another example, when answering the phone, the tourist doesn't express clearly resulting in poor communication. Even so, outbound tour leader still should apologize and inform the tourists: 'I am so sorry and I can't hear clearly, so would you please repeat it?' instead of blaming the tourist's lisp. Hence, by blaming on themselves and showing more understand to tourists, the outbound tour leaders can enhance customer satisfaction.

\subsubsection{Help Tourists Make Choice}

In the process of service, tourists' dilemma may lead to a poor communication even difficulty in making a choice. When tourists encounter choice problems, the leader should remember the solution principle namely a Chinese old saying: when facing benefits, choose the more beneficial one and when facing both disadvantages, choose the less one. That is, before making a choice, if the tourists like the both items, they will choose a relatively more favorite one; if they don't like either item, they will choose a relatively less offensive one. First of all, the leader should have a wealth of cross cultural knowledge. After a comprehensive introduction of products, resources, leaders should show their advantages and disadvantages clearly and help visitors make a choice with the above-mentioned solution principle: 'Do you need.. or...?' by enumerating items together rather than one by one which will effectively help tourists to solve the choice problem.

One of the responsibilities of the leaders is to encourage tourism products sales. They can guide the tourists to make choice of local specialties by 'the solution principle'. There is a comparison between two sale languages:

(1) 'Do you need A?' the tourists answer: don't; 'Do you need B?' tourists still answer: don't; 'Do you need C?' tourists answer once more: don't.

(2) 'In these three kinds of products, do you need A, B or C?', tourists may purchase at least one item of them.

Why the second expression can more trigger tourists to purchase than the first one? The reason is that from a psychological point of view, when the tour leader makes good use of the solution principle 
and shows all products together instead of one by one, the tourists will make comparison among them carefully from personal preference, which can effectively help the tourists solve the problem of making choice and promote tourism product sales.

\subsubsection{Encourage the tourists}

James William, a psychologist, believes that it is the most basic nature of human desire to be appreciated. When visitors come to a foreign country, they will have psychological discomfort caused by cultural differences. Leaders should encourage them, express appreciation and praise, which will effectively reduce the psychological discomfort of tourists.

The greatest salesman in the world, Joe Girard excels at using words of praise. But he also mentioned that the praise should connect to the facts and the words of compliments should be expressed varying from person to person. For example, when leaders see the younger generation and the elders, they can praise filial piety of the younger generation and good health of the elders; when meeting couples, they can praise their harmonious relationship; when meeting babies with parents, they can praise the lovely children, and so on. Public relations experts believe that praise is like sunlight to the human spirit. Without a doubt, appreciating or encouraging the tourists, the outbound tour leader may establish friendly relationship with them.

\subsubsection{Make Visitors feel the outbound tour leader's Efforts}

In a foreign country, the tourists are often prone to be nervous, upset, and even irritable when waiting for a long time in the process of customs registration, waiting for the check-in procedures in the hotel and waiting for the available seats in the restaurant. During the above-mentioned process, the leader should communicate with visitors, timely inform them the progress and shouldn't blindly said 'no, not yet, not yet,' and so on. Instead, they should say: 'I am communicating with the staff/officers and they are doing their endeavor to solve this matter, so it should be quickly resolved. Don't worry about it'. In other words, don't tell tourists 'work has not yet been completed or problem is not resolved', but to show tourists how the outbound tour leader is trying his/her best to solve the problem. As a result, the outbound tour leader will win the understanding and support and avoid disputes triggered by the tourists' impulsive emotions due to long waiting time.

\subsubsection{Pay Attention to the Guidance Strategy}

Because the tourists are in a foreign country, they are not familiar with the western etiquette or local etiquette, so the tour leader should conduct tourists to be courteous abroad. Tourist is not the one to be preached, but the one to be served. When finding inappropriate behaviors of the tourists, the outbound tour leader should correctly conduct tourists and change the expression from 'can't do' to 'can do' and eliminate the impolite warnings and inform the tourist what is reasonable and legitimate, and guide the tourists polite travelling, help them avoid violating the local laws and regulations in a foreign country. For example, when the tourists are found smoking in a non-smoking area, the tour leader cannot warn them: 'can't / no smoking here!' but to offer guidance: 'you can smoke in the smoking area.' and show where it is.

\subsubsection{Take 'Yes....But'Strategy}

For example, in a foreign country, the leader will generally take tourists to a familiar restaurant for dining, and introduces the characteristics of dishes, when tourists pointed out that: 'everything is good, but the price is high', leaders at this time should not be blindly against by saying 'what you say is wrong and it's not expensive'. It is easy to form a confrontation with the tourists. Conversely, the leaders should first agree on it: 'yes, what you said is reasonable. Comparing with other restaurants, it is a little more expensive, but...', that is, it will reach a consensus with the tourists by the word 'YES', and the meaning behind the word 'BUT' is really what the tour leader wants to express, which is the value of choosing this restaurant. First taking positive expression to inform the tourists that they hold the same opinions is easy to trigger a tourist's resonance, and in the case of not causing the tourists' antipathy to offer guidance on their consumption. 


\section{Suggestions on Building the Language Ability of Outbound Tour Leader}

To build language skills, outbound tour leader, should not simply learn language and grasp language application skills, but pay attention to the following aspects:

\subsection{Strengthen Language Application Ability}

Outbound tour leader should strengthen the ability of language application, oral communication and writing ability. In a foreign country, how to pronounce correctly is not most difficult but accurate language application. The language application ability includes the translation, interpretation and expression ability, service and coordination ability, and the professional attitude and approach to accurately grasp the characteristics of items narrated. The tour leader could enhance the application and communication skills with the aforementioned six skills.

\subsection{Enhance Cross-cultural Sensitivity}

Linguists believe that cross-cultural sensitivity directly affects the effectiveness of intercultural communication. People with higher cross-cultural sensitivity always exhibit more self-esteem behavior, have a stronger compression and anti-frustration ability and better environmental adaptability, who can calmly deal with the cultural differences in the process of intercultural communication. Therefore, cross-cultural sensitivity can help outbound tour leader better understand foreign culture, reduce cultural prejudice and differences. Therefore, in addition to the accumulation of vocabulary, reading, listening and speaking, the tour leader may pay attention to the details of foreign cultures and find more opportunities of international communication to enhance cross-cultural sensitivity.

\subsection{Intensify Intercultural Communication Competence}

The leader's language not only includes dialects and the general-purpose language, but also includes foreign language, which are basic language. The connotation of Chinese and Western culture is the key of the language. The leader should serve, better communicate with and understand tourists, so they need deepen the understanding of foreign culture, including history, geography, customs, values, explicit behavior, etc. The leader should have initiative to appreciate culture, understand culture, and even facilitate the cultural interchange. Accordingly, the leader should grasp outbound tourists' cultural taste and aesthetic taste accurately. They should absorb the essence of culture from the historical figures, custom story, news events and local elites' legends, understand the similarities and differences of the native culture, which can be integrated into the service so as to guide tourists to appreciate foreign culture and reduce its impetuous mood in foreign country and broaden their horizon.

\subsection{Improve Service Ability}

In essence, enhancing outbound tour leader's service awareness and ability is key to better using the above language skills. Especially, they should pay much heed to the psychology of 'first impression', which means a good beginning is half done. In the communication, besides language skills, the tour leader should make good use of appropriate language norms and international etiquette; furthermore, they should control their temper, and show their respect for the tourists. Therefore, besides the language skills, combining with friendly gestures, smiles, eyes and other body languages, the leader will make tourists be satisfied by the communication, moreover, leaders also need carefully ponder the skills of service language and seriously think about the situation and timing of language using. Language competence is promoted; service ability is also improved at the same time, thus forming a virtuous cycle of high quality service and good language ability.

\section{Conclusion}

Outbound tour leader plays a key role in helping tourists communicate in foreign country, so the leader's language ability has become an important bridge for cultural exchange and communication. Leader's language ability includes the general language ability, namely dialect expression ability, general-purpose language application ability, interpretation and translation ability, and communication ability, namely six language communication skills. Obviously, the above abilities 
can't be got simply by training and language learning, but by strengthening language application ability, enhancing the intercultural sensitivity, intensifying intercultural communication competence and improving the service ability, and so on.

\section{Acknowledgments}

This paper aided financially by the Research Project of Education Department of Hainan Province (NO.Hnjg2015-75)(A Study on the Course Construction of 'Outbound Tour Leader Service'--Based on the Co-construction and Sharing Excellent Course Resources of the Open University of China.)

\section{References}

[1] Yang zhong, Li Qinghe. Meaning, Connotation and Translation: A Discussion on the Hierarchy and Relativity of Translation Equivalence. Chinese Translators Journal, Vol.5 (1995) No. 5, p. $12-15$.

[2] Yuyi Mengting. On Linguistic and Cultural Untranslatability and Their Translation Strategies and Approaches-Taking the Comparison and Analysis of the Two English Translations of Hong Lou Meng for Illustration (Master's Degree. Guangxi Normal University, China 2008). P.5-8.

[3] Ding Chuang. On Foreign Tour Guides' Awareness of Cross-cultural Communication in Their Translation. Journal of Shenyang Agricultural University(Social Sciences Edition), Vol.10 (2008) No.4, p.485-488.

[4] Zhang Haizhong, Zhang Pengying. A Theoretical Exploration and Empirical Research on the Fellow-Townsman Reference Effect in China. Advances in Psychological Science, Vol.8(2012), p. 1237-1242.

[5] Chen, G. M. \& Starosta, W. J. A Review of the Concept of Intercultural Awareness. Human Communication. Vol. 9 (1998). No. 2.p.27-38.

[6] Xuan Niannian. Inter-cultural Language Conversion Strategies Used in Tour Guides Interpreting. Overseas English, Vol. (2012), p174-175. 